\title{
Synthesis of $\mathrm{CaTiO}_{3}$ from calcium titanyl oxalate hexahydrate (CTO) as precursor employing microwave heating technique
}

\author{
B M PATIL, R S SRINIVASA ${ }^{\dagger}$ and S R DHARWADKAR* \\ Department of Chemistry, The Institute of Science, 15, Madam Cama Road, Mumbai 400 032, India \\ ${ }^{\dagger}$ Department of Metallurgical Engineering \& Materials Science, Indian Institute of Technology, \\ Mumbai 400 076, India
}

MS received 30 June 2006; revised 16 April 2007

\begin{abstract}
Calcium titanate, $\mathrm{CaTiO}_{3}$, an important microwave dielectric material and one of major phases in synroc (synthetic rock), a titanate ceramic with potential application for fixation of high level nuclear waste was synthesized from calcium titanyl oxalate $\left[\mathrm{CaTiO}\left(\mathrm{C}_{2} \mathrm{O}_{4}\right)_{2} \cdot 6 \mathrm{H}_{2} \mathrm{O}\right]$ (CTO) by employing microwave heating technique. CTO heated in microwave heating system in air at $500^{\circ} \mathrm{C}$ for $1 \mathrm{~h}$ gave a perovskite, $\mathrm{CaTiO}_{3}$. $\mathrm{The}$ product obtained by heating of CTO in the same system at $700^{\circ} \mathrm{C}$ for the same duration was however, much more crystalline. $\mathrm{CaTiO}_{3}$ obtained by the present method was characterized by X-ray diffraction (XRD), scanning electron microscopy (SEM) and BET surface area measurement.
\end{abstract}

Keywords. Ceramics; synroc; perovskites; electronic materials; microwave synthesis; $\mathrm{CaTiO}_{3}$.

\section{Introduction}

Calcium titanate, $\mathrm{CaTiO}_{3}$, with perovskite structure is one of the major phases in Synroc (synthetic rock), a titanate ceramic used for immobilization of high-level nuclear waste (Ringwood et al 1979, 1988). It is the major host matrix for strontium, an important radwaste element and can also incorporate significant amounts of lanthanides and actinides (Hanajiri et al 1997, 1998). In addition to these nuclear applications, it also finds applications in several electronic devices operating at microwave frequency by virtue of its excellent dielectric properties (Kim et al 1999; Suvorov et al 2000, 2001; Huang et al 2001).

Various methods have been reported in the literature for the synthesis of $\mathrm{CaTiO}_{3}$. These include (i) conventional ceramic technique (Kay and Bailey 1957; Redfern 1996), (ii) organometallic (Yang et al 1985), (iii) liquid mix method (Balchandran et al 1982; Pan et al 2003), (iv) chemical co-precipitation method (Gopalakrishnamurty et al 1975), (v) combustion method (Muthuraman and Patil 1994) and (vi) organic-inorganic solution technique (Lee et al 2004). Among these methods, the conventional ceramic technique requires high temperatures $\left(>1200^{\circ} \mathrm{C}\right)$ and prolonged heating of the reaction components to get the product (Kay and Bailey 1957; Redfern 1996). In other methods, the reaction components are generated in situ and are more reactive. Moreover, the particle-to-particle contact in these cases is also more intimate, facilitating the reaction at much lower temperatures. Several other

*Author for correspondence (srdharwadkar@hotmail.com) methods involving the mechanical activation of the reactants have also been proposed to reduce the temperature of the reaction (Mi et al 1998, 1999; Evans et al 2003; Vukotic et al 2004).

In the present paper, we have attempted to synthesize $\mathrm{CaTiO}_{3}$ from calcium titanyl oxalate (CTO) by heating it in a microwave heating system as well as in a silicon carbide furnace. The product obtained was characterized by X-ray diffraction (XRD), SEM and BET surface area measurement.

\section{Experimental}

\subsection{Synthesis of calcium titanyl oxalate (CTO)}

CTO used in the present study was synthesized by chemical co-precipitation method. All the chemicals used were of AnalaR grade. In this method, $\mathrm{CaCO}_{3}$ was dissolved in equimolar aqueous solution of $\mathrm{TiOCl}_{2}$ with constant stirring. This mixture was added to aqueous solution of oxalic acid to maintain the mole ratio $\mathrm{Ca}: \mathrm{Ti}$ : oxalic acid as $1: 1: 2$. The aqueous solution was kept over sodium hydroxide pellet in a desiccator for 4 to 5 days when a white precipitate was obtained. The precipitate was filtered through Buckner funnel, washed thoroughly first with distilled water and then with acetone and dried in air. Based on chemical analysis, the product could be assigned the molecular formula, $\mathrm{CaTiO}\left(\mathrm{C}_{2} \mathrm{O}_{4}\right)_{2} \cdot 6 \mathrm{H}_{2} \mathrm{O}$. The X-ray diffraction pattern recorded for the product showed that it was amorphous and also no lines of calcium oxalate and titanyl oxalate were visible. 


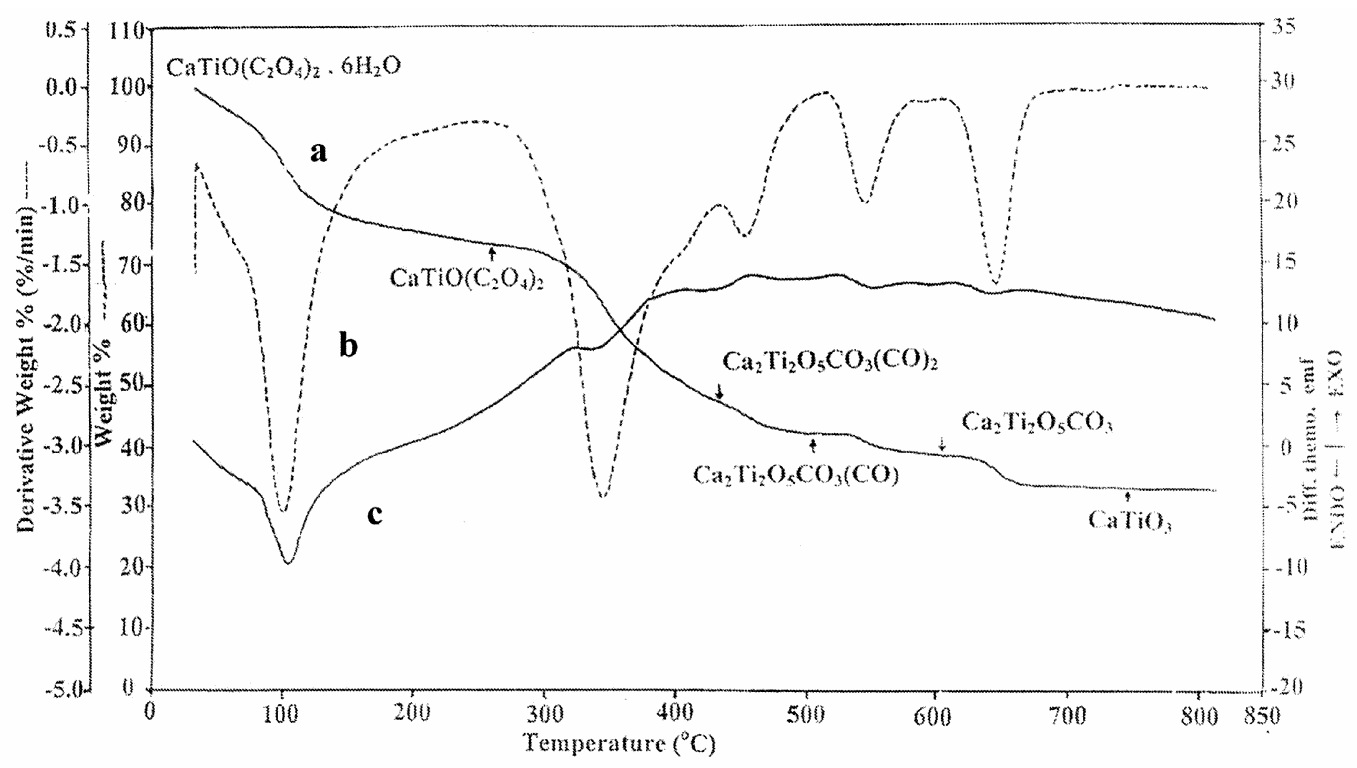

Figure 1. Simultaneous a. TG, b. DTG and c. DTA of calcium titanyl oxalate (CTO) in flowing nitrogen.

2.2 Thermogravimetry (TG), derivative thermogravimetry (DTG) and differential thermal analysis (DTA) of CTO

The simultaneous TG-DTG-DTA curves of CTO were recorded on $2.380 \mathrm{mg}$ of sample in nitrogen at a heating rate of $10^{\circ} \mathrm{C} \mathrm{min}{ }^{-1}$ using the DIAMOND TG-DTA (Perkin Elmer, Germany) Instrument.

\subsection{Preparation of calcium titanate $\left(\mathrm{CaTiO}_{3}\right)$}

Calcium titanate was prepared by heating CTO in a microwave heating system as well as in a silicon carbide furnace. CTO was heated in a microwave heating system at temperatures of $500^{\circ} \mathrm{C}$ and $700^{\circ} \mathrm{C}$ for $1 \mathrm{~h}$. Also CTO was heated in a silicon carbide furnace at $500^{\circ} \mathrm{C}$ and $700^{\circ} \mathrm{C}$ for the same period. The product obtained after heat treatment at different temperatures was analysed by X-ray diffraction using X-PERT X-ray diffractometer, Phillips, at a scanning rate of $1^{\circ} 2 \theta \mathrm{min}^{-1}$, using monochromatic X-ray beam of wavelength, $0 \cdot 15405 \mathrm{~nm}$.

\section{Results and discussion}

3.1 Thermogravimetry (TG), derivative thermogravimetry (DTG) and differential thermal analysis (DTA) of CTO

The TG, DTG and DTA curves of CTO recorded in nitrogen at a heating rate of $10^{\circ} \mathrm{C} / \mathrm{min}$ are shown in figures $1 \mathrm{a}, \mathrm{b}$ and $\mathrm{c}$, respectively. These data indicate that CTO decomposes in five steps involving dehydration, decarboxylation to intermediate carbonate and decomposition carbonates to give
$\mathrm{CaTiO}_{3}$ as the final product above $650^{\circ} \mathrm{C}$. The endothermic peak in DTA curve located around $105^{\circ} \mathrm{C}$ could be attributed to dehydration of six water molecules to form anhydrous CTO represented by (1). An endothermic peak in the temperature range $300-400^{\circ} \mathrm{C}$ is followed by two weak exothermic peaks observed in the range $400-600^{\circ} \mathrm{C}$, which could have resulted due to decomposition of carboxylate and simultaneous oxidation of evolved $\mathrm{CO}[(2)$, (3) and (4)]. Finally, an endotherm is observed at $650^{\circ} \mathrm{C}$ indicating the formation of $\mathrm{CaTiO}_{3}$ phase according to (5). TG, DTG and DTA indicate that the thermal decomposition of CTO to form $\mathrm{CaTiO}_{3}$ in nitrogen atmosphere involves the following sequence of steps.

$$
\begin{aligned}
& \mathrm{CaTiO}\left(\mathrm{C}_{2} \mathrm{O}_{4}\right)_{2} \cdot 6 \mathrm{H}_{2} \mathrm{O} \rightarrow \mathrm{CaTiO}\left(\mathrm{C}_{2} \mathrm{O}_{4}\right)_{2}+6 \mathrm{H}_{2} \mathrm{O} \\
& 2 \mathrm{CaTiO}\left(\mathrm{C}_{2} \mathrm{O}_{4}\right)_{2} \rightarrow \mathrm{Ca}_{2} \mathrm{Ti}_{2} \mathrm{O}_{5} \mathrm{CO}_{3}(\mathrm{CO})_{2}+3 \mathrm{CO}_{2}+2 \mathrm{CO} \\
& \mathrm{Ca}_{2} \mathrm{Ti}_{2} \mathrm{O}_{5} \mathrm{CO}_{3}(\mathrm{CO})_{2} \rightarrow \mathrm{Ca}_{2} \mathrm{Ti}_{2} \mathrm{O}_{5} \mathrm{CO}_{3}(\mathrm{CO})+\mathrm{CO} \\
& \mathrm{Ca}_{2} \mathrm{Ti}_{2} \mathrm{O}_{5} \mathrm{CO}_{3}(\mathrm{CO}) \rightarrow \mathrm{Ca}_{2} \mathrm{Ti}_{2} \mathrm{O}_{5} \mathrm{CO}_{3}+\mathrm{CO} \\
& \mathrm{Ca}_{2} \mathrm{Ti}_{2} \mathrm{O}_{5}\left(\mathrm{CO}_{3}\right)_{2} \rightarrow 2 \mathrm{CaTiO}_{3}+\mathrm{CO}_{2}
\end{aligned}
$$

The five steps involved in the decomposition scheme presented here are based on the stoichiometry of the reaction steps deduced from the mass changes observed in TG. However, the proposed decomposition scheme needs independent support from other complementary techniques like evolved gas analysis. Simultaneous TG-MS studies are in progress to resolve this issue. From the TG and DTA curves it was concluded that the formation of $\mathrm{CaTiO}_{3}$ from CTO precursor was complete above $650^{\circ} \mathrm{C}$. It is interesting to note that in the second and third steps of 


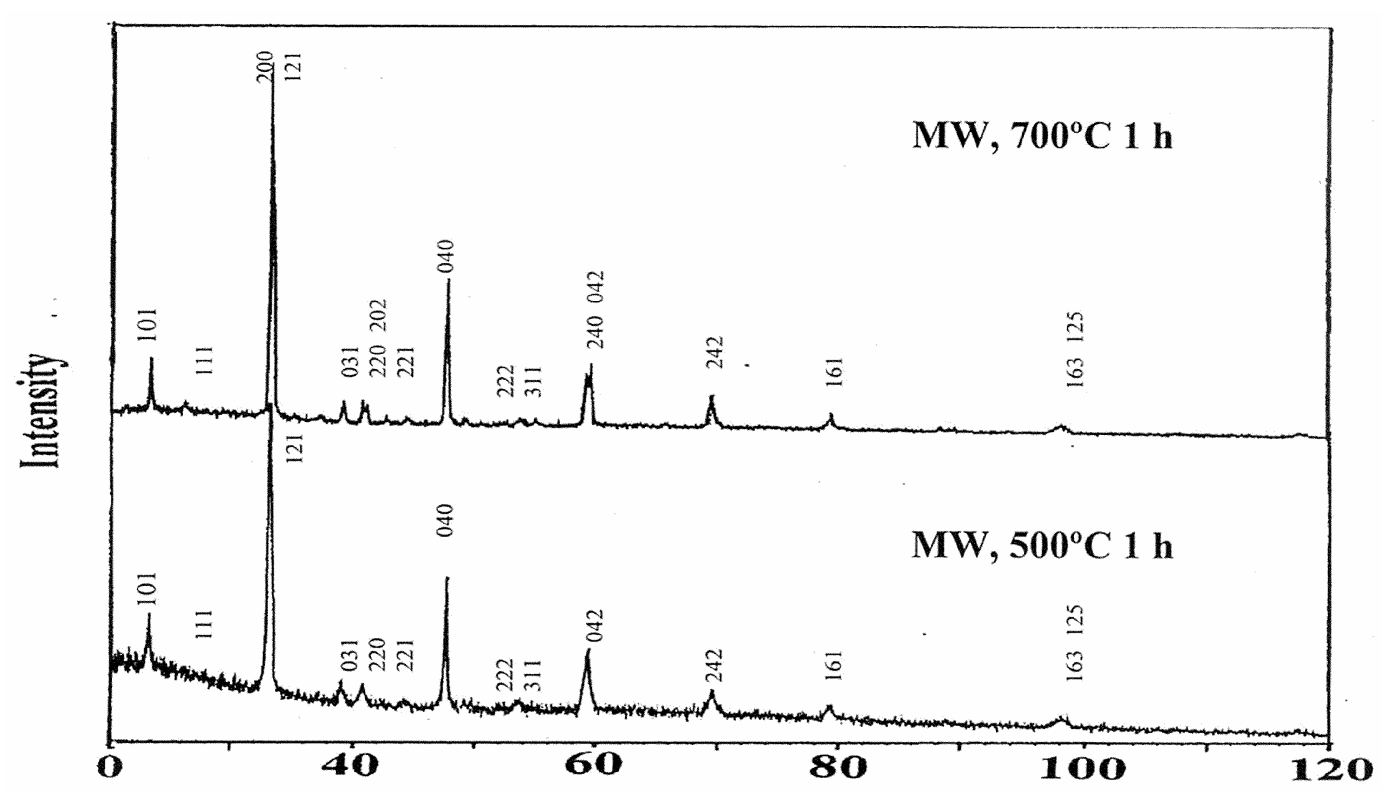

Figure 2. XRD pattern of CTO heated in microwave heating system at a. $500^{\circ} \mathrm{C}$ and b. $700^{\circ} \mathrm{C}$ for $1 \mathrm{~h}$.

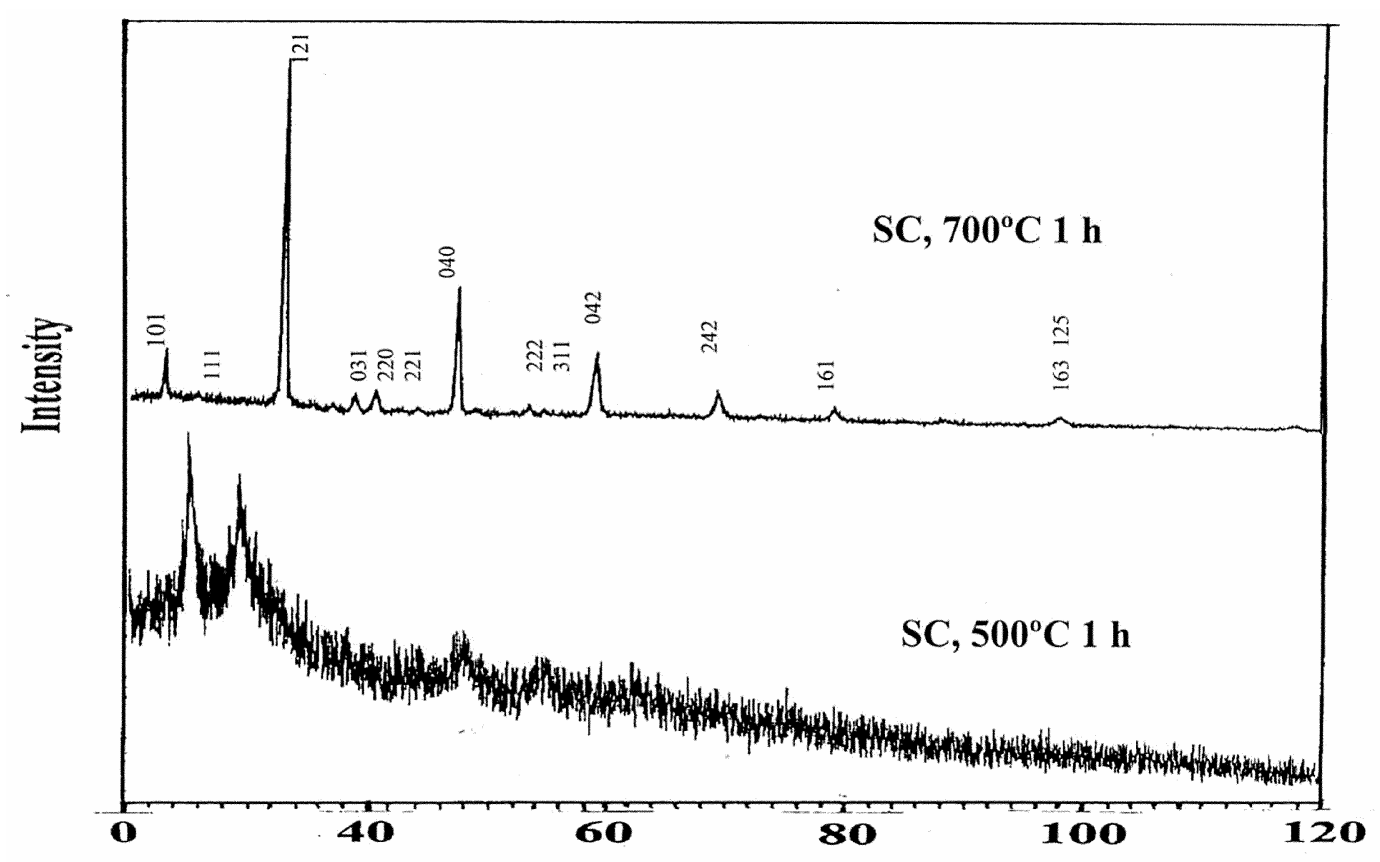

Figure 3. XRD pattern of CTO heated in silicon carbide furnace at a. $500^{\circ} \mathrm{C}$ and b. $700^{\circ} \mathrm{C}$ for $1 \mathrm{~h}$.

decomposition of CTO, carbon monoxide is evolved as the gaseous product, which could provide reducing atmosphere in the vicinity of the sample, thereby reducing $\mathrm{Ti}^{4+}$ partially to $\mathrm{Ti}^{3+}$ which interacts strongly with microwave (Agrawal 1998; Malghe et al 2004).

\subsection{X-ray diffraction patterns}

The X-ray diffraction patterns of CTO calcined in microwave heating system at temperatures $500^{\circ} \mathrm{C}$ and $700^{\circ} \mathrm{C}$, for
$1 \mathrm{~h}$ are shown in figures $2 \mathrm{a}$ and $\mathrm{b}$. The corresponding patterns of the product obtained by heating CTO in silicon carbide furnace at $500^{\circ} \mathrm{C}$ and $700^{\circ} \mathrm{C}$ for the same duration are shown in figures $3 \mathrm{a}$ and $\mathrm{b}$. The CTO calcined in microwave heating system at a temperature as low as $500^{\circ} \mathrm{C}$ for $1 \mathrm{~h}$ (figure 2a) showed the formation of pure perovskite, $\mathrm{CaTiO}_{3}$. The product obtained by heating the same precursor at $700^{\circ} \mathrm{C}$ in microwave heating system for $1 \mathrm{~h}$ was found to be much more crystalline compared to that obtained at $500^{\circ} \mathrm{C}$. However, calcination of CTO in silicon 
carbide furnace at $500^{\circ} \mathrm{C}$ for $1 \mathrm{~h}$ could not form the product, $\mathrm{CaTiO}_{3}$, as shown in figure $3 \mathrm{a}$. This is also corrobo-
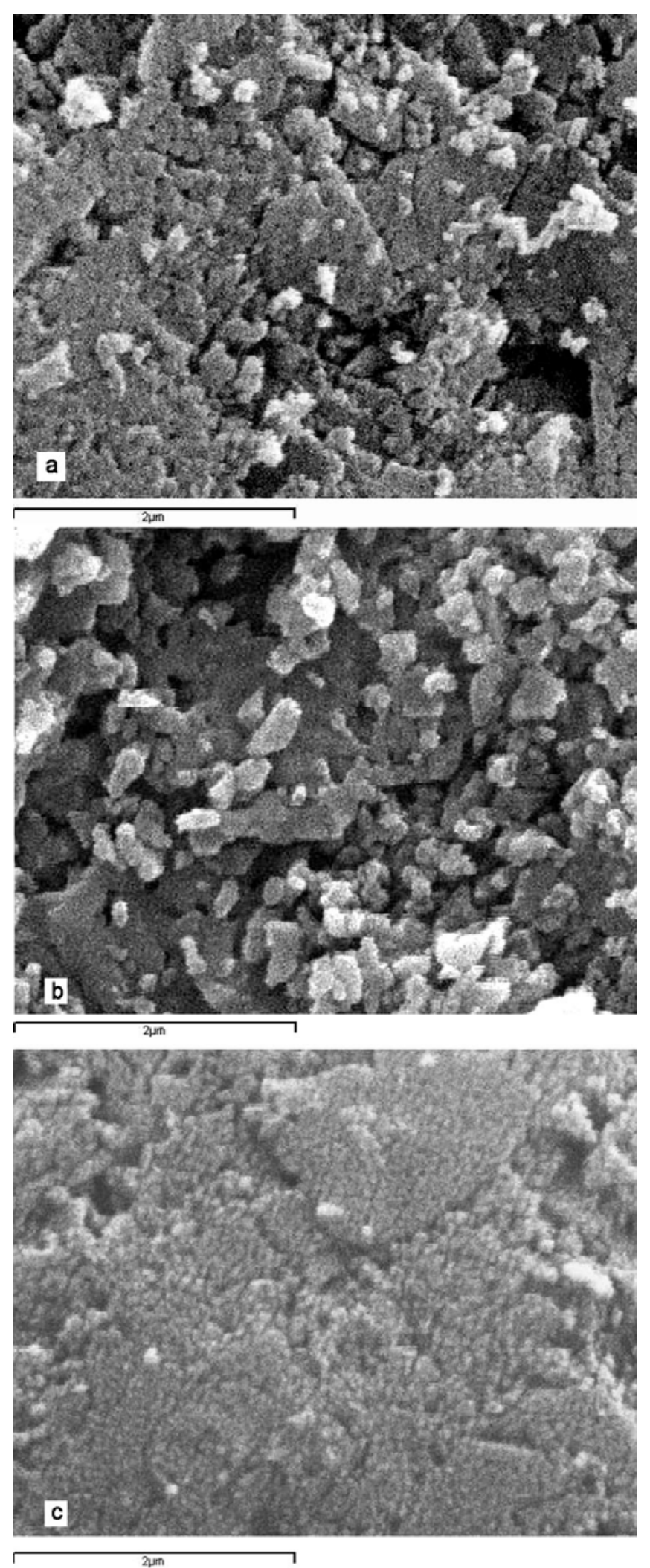

Figure 4. SEM photographs of $\mathrm{CaTiO}_{3}:$ a. $\mathrm{MW}, 500^{\circ} \mathrm{C} 1 \mathrm{~h}$, b. MW, $700^{\circ} \mathrm{C} 1 \mathrm{~h}$ and c. silicon carbide furnace, $700^{\circ} \mathrm{C} 1 \mathrm{~h}$. rated from the TG curve (figure 1a), which indicates that the reaction involving the formation of $\mathrm{CaTiO}_{3}$ is not completed at this temperature. The calcination of $\mathrm{CTO}$ in silicon carbide furnace at $700^{\circ} \mathrm{C}$ for $1 \mathrm{~h}$ was found to yield $\mathrm{CaTiO}_{3}$ which was as crystalline as the product obtained by microwave heating at $500^{\circ} \mathrm{C}$ for the same duration (figure $3 b)$. The results indicate that the temperature of synthesis of $\mathrm{CaTiO}_{3}$ is lowered considerably by employing microwave heating.

The results presented in the foregoing sections indicate that perovskite, $\mathrm{CaTiO}_{3}$, could be synthesized by heating $\mathrm{CTO}$ at a temperature as low as $500^{\circ} \mathrm{C}$. The reducing atmosphere provided by the evolved carbon monoxide [(2) and (3)] could perhaps be responsible to yield non-stoichiometric $\mathrm{TiO}_{2}$, which subsequently reacted at low temperatures to form $\mathrm{CaTiO}_{3}$.

Our present observations indicate that the lowering of reaction temperature in microwave heating could be the result of two independent factors, which include the interaction of microwave with defects, involving the role of oxygen vacancies and a number of unpaired electrons present in reactants. In the decomposition of CTO, carbon monoxide is evolved as the gaseous product, which could provide reducing atmosphere in the vicinity of the sample, to yield hypostoichiometric $\mathrm{TiO}_{2}$ that interacts strongly with microwave, facilitating the solid-state reaction at a much lower temperature. Further, the unpaired electrons in reduced $\mathrm{Ti}$ ion i.e. in $\mathrm{Ti}^{3+}$, could facilitate stronger interaction with the magnetic component of the microwave thereby augmenting the reaction rate and lowering the reaction temperature (Dharwadkar 2006).

The SEM photographs of $\mathrm{CaTiO}_{3}$ prepared by heating $\mathrm{CTO}$ at $500^{\circ} \mathrm{C}$ and $700^{\circ} \mathrm{C}$ for $1 \mathrm{~h}$ using microwave heating system are shown in figures $4 a$ and $b$. A similar photograph for $\mathrm{CaTiO}_{3}$ prepared by heating CTO in a silicon carbide furnace at $700^{\circ} \mathrm{C}$ for $1 \mathrm{~h}$ is shown in figure 4c. These photographs indicate that $\mathrm{CaTiO}_{3}$ prepared at $500^{\circ} \mathrm{C}$ in microwave heating system yields material of very fine particle size. It can be concluded from these figures that an average particle size of the product obtained by microwave heating increased on increasing the temperature from $500-700^{\circ} \mathrm{C}$. The product obtained by heating the precursor to $700^{\circ} \mathrm{C}$ in air, however, had much finer particle size (figure 3c) compared to that obtained at the same temperature by microwave heating (figure $3 b$ ), indicating that the fine particle product obtained at low temperature $\left(500^{\circ} \mathrm{C}\right)$ by microwave heating sintered much more rapidly with increasing temperature. This is supported by the surface area measurements made by BET

Table 1. Surface area of $\mathrm{CaTiO}_{3}$ prepared by different methods.

Method of heating Temperature $\left({ }^{\circ} \mathrm{C}\right)$ Surface area $\left(\mathrm{m}^{2} / \mathrm{g}\right)$

\begin{tabular}{lrr}
\hline Microwave heating & 500 & 11.78 \\
& 700 & 5.56 \\
Silicon carbide furnace & 700 & 8.65 \\
\hline
\end{tabular}


gas adsorption technique. The values of surface area listed in table 1, indicate that the surface area of the product obtained by heating the precursor to $700^{\circ} \mathrm{C}$ in air is higher than that obtained at the same temperature for the same time duration in the microwave heating.

\section{Conclusions}

Synthesis of $\mathrm{CaTiO}_{3}$ reported by earlier investigators (Kay and Bailey 1957; Redfern 1996) required high temperature $\left(>1200^{\circ} \mathrm{C}\right)$ and long heating periods (more than $12 \mathrm{~h}$ ). Muthuraman and Patil (1994) synthesized $\mathrm{CaTiO}_{3}$ at $500^{\circ} \mathrm{C}$ by combustion method but the product obtained was amorphous and further heat treatment at about $900^{\circ} \mathrm{C}$ was required for crystallization. We adopted a new method in which crystalline $\mathrm{CaTiO}_{3}$ was synthesized from CTO heated in microwave heating system at $500^{\circ} \mathrm{C}$ within an hour. These observations indicate that the microwave heating facilitates the formation of $\mathrm{CaTiO}_{3}$ from $\mathrm{CTO}$ precursor at much lower temperatures.

\section{Acknowledgements}

Authors are thankful to the Materials Science Section, Tata Institute of Fundamental Research (TIFR), Mumbai, for recording the SEM photographs of the samples.

\section{References}

Agrawal D K 1998 Curr. Opinion Solid State and Mater. Sci. 3480 Balchandran V, Odekirk B and Eror N G 1982 J. Mater. Sci. 17 1656

Dharwadkar S R 2006 Indo-US workshop on microwave technology for medical processing - A promising option for tomorrow, Mumbai, ASTM-International, Indian Chapter, p. 53
Evans I R, Howard J A K, Screkovic T and Ristic M M 2003 Mater. Res. Bull. 381203

Gopalakrishnamurty H S, Subba Rao M and Narayan Kutty T R 1975 Thermochim. Acta 13183

Hanajiri Y, Yoka H, Mutsui T, Arita Y, Nagasaki T and Shigematsu H 1997 J. Nucl. Mater. 247285

Hanajiri Y, Yoka H, Mutsui T, Arita Y, Nagasaki T and Shigematsu H 1998 Solid State Ionics 108345

Huang C L, Chen H L and Wu C C 2001 Mater. Res. Bull. 36 1645

Kay H F and Bailey P C 1957 Acta Crystallogr. 10219

Kim W S, Cheon C I, Kang H J, Lee C H, Kim K Y, Nam N and Byun J 1999 Jpn J. Appl. Phys. 385633

Lee S J, Kim Y C and Hwang J H 2004 J. Ceram. Proc. Res. 5 223

Malghe Y S, Gurjar A V and Dharwadkar S R 2004 Bull. Mater. Sci. 27217

Mi G, Saito F, Suzuki S and Waseda Y 1998 Powder Technol. 97178

Mi G, Murakimi Y, Saito F, Shindo D and Suzuki S 1999 Powder Technol. 105162

Muthuraman M and Patil K C 1994 Mater. Res. Bull. 17977

Pan Y, Su Q, Xu H, Chen T, Ge W, Yang C and Wu M 2003 J. Solid State Chem. 17469

Redfern S A T 1996 J. Phys. Condens. Matter 88267

Ringwood A E, Kesson S E, Ware N G, Hibberson W and Majar A 1979 Nature 278219

Ringwood A E, Kesson S E, Reeve K D, Levins D M and Rann E J 1988 in Radioactive waste forms for future (eds) W Lutre and R C Ewing (Amsterdam: Elsevier) p. 233

Suvorov D, Drazic G, Valant M and Janear B 2000 Korean J. Cryst. 11195

Suvorov D, Valant M, Jancar B and Skapin S D 2001 Acta Chim. Slov. 4887

Vukotic V M, Screckovic T, Marinkovic Z V, Brankovic G, Cilense M and Arandjelovic D 2004 Mater. Sci. Forum 453454429

Yang Z Z, Yamada H and Miller G R 1985 J. Solid State Chem. 41185 